\title{
Role of caregiver factors in outpatient medical follow-up post-stroke: observational study in Singapore
}

Shilpa Tyagi ${ }^{1}$, Gerald Choon-Huat Koh ${ }^{1 *}$, Nan Luo ${ }^{1}$, Kelvin Bryan Tan ${ }^{2}$, Helen Hoenig ${ }^{3}$, David B. Matchar ${ }^{4}$, Joanne Yoong ${ }^{1}$, Angelique Chan ${ }^{4}$, Kim En Lee ${ }^{5}$, N. Venketasubramanian ${ }^{6}$, Edward Menon ${ }^{7}$, Kin Ming Chan ${ }^{8}$, Deidre Anne De Silva ${ }^{9}$, Philip Yap ${ }^{10}$, Boon Yeow Tan ${ }^{11}$, Effie Chew ${ }^{12}$, Sherry H. Young ${ }^{13}$, Yee Sien Ng ${ }^{14}$, Tian Ming Tu ${ }^{15}$, Yan Hoon Ang ${ }^{10}$, Keng He Kong ${ }^{16}$, Rajinder Singh ${ }^{15}$, Reshma A. Merchant ${ }^{17}$, Hui Meng Chang ${ }^{9}$, Tseng Tsai Yeo ${ }^{18}$, Chou Ning ${ }^{18}$, Angela Cheong ${ }^{1}$, Yu Li Ng${ }^{2}$ and Chuen Seng Tan ${ }^{1}$

\begin{abstract}
Background: Outpatient medical follow-up post-stroke is not only crucial for secondary prevention but is also associated with a reduced risk of rehospitalization. However, being voluntary and non-urgent, it is potentially determined by both healthcare needs and the socio-demographic context of stroke survivor-caregiver dyads. Therefore, we aimed to examine the role of caregiver factors in outpatient medical follow-up (primary care (PC) and specialist outpatient care (SOC)) post-stroke.
\end{abstract}

Method: Stroke survivors and caregivers from the Singapore Stroke Study, a prospective, yearlong, observational study, contributed to the study sample. Participants were interviewed 3-monthly for data collection. Counts of PC and SOC visits were extracted from the National Claims Database. Poisson modelling was used to explore the association of caregiver (and patient) factors with PC/SOC visits over 0-3 months (early) and 4-12 months (late) post-stroke.

Results: For the current analysis, 256 stroke survivors and caregivers were included. While caregiver-reported memory problems of a stroke survivor (IRR: 0.954; 95\% Cl: 0.919, 0.990) and caregiver burden (IRR: 0.976; 95\% Cl: 0.959, 0.993) were significantly associated with lower early post-stroke PC visits, co-residing caregiver (IRR: 1.576; 95\% Cl: 1.040, 2.389) and negative care management strategies (IRR: 1.033; 95\% Cl: 1.005, 1.061) were significantly associated with higher late post-stroke SOC visits.

Conclusion: We demonstrated that the association of caregiver factors with outpatient medical follow-up varied by the type of service (i.e., PC versus SOC) and temporally. Our results support family-centred care provision by family physicians viewing caregivers not only as facilitators of care in the community but also as active members of the care team and as clients requiring care and regular assessments.

Keywords: Primary care, Caregivers, Stroke, Healthcare utilization, Family caregivers

\footnotetext{
*Correspondence: gerald_koh@nuhs.edu.sg

1 Saw Swee Hock School of Public Health, National University

of Singapore, 12 Science Drive 2, \#10-01, Singapore 117549, Singapore

Full list of author information is available at the end of the article
}

(C) The Author(s) 2021. Open Access This article is licensed under a Creative Commons Attribution 4.0 International License, which permits use, sharing, adaptation, distribution and reproduction in any medium or format, as long as you give appropriate credit to the original author(s) and the source, provide a link to the Creative Commons licence, and indicate if changes were made. The images or other third party material in this article are included in the article's Creative Commons licence, unless indicated otherwise in a credit line to the material. If material is not included in the article's Creative Commons licence and your intended use is not permitted by statutory regulation or exceeds the permitted use, you will need to obtain permission directly from the copyright holder. To view a copy of this licence, visit http://creativecommons.org/licenses/by/4.0/. The Creative Commons Public Domain Dedication waiver (http://creativeco mmons.org/publicdomain/zero/1.0/) applies to the data made available in this article, unless otherwise stated in a credit line to the data. 


\section{Background}

Stroke presents a major public health challenge accounting annually for 16 million cases and 5.7 million deaths globally [1].Stroke is the third largest contributor of DALYs [2], the tenth most common cause of hospitalization [3] and one of the top five causes of death in Singapore [4]. Treatment of stroke comprises of an acute and sub-acute or early chronic phase. While the acute phase includes emergency care in a tertiary inpatient setting, the sub-acute or early chronic phase comprises rehabilitation and outpatient medical follow-up to ensure continuity of care and implement secondary prevention practices. The outpatient medical follow-up usually occurs in a primary care (PC) setting involving a family physician. Researchers in a study reported family physicians (93.2\%) to be the most frequently visited healthcare professional post-stroke, followed by other medical specialists (54\%) [5].

Being voluntary and non-urgent, outpatient medical follow-up in PC or specialist outpatient care (SOC) setting is potentially determined by both healthcare needs and overall socio-demographic context of caregivers and stroke survivors. Moreover, stroke survivors often have residual impairments of varying magnitude, which make it challenging to attend outpatient medical visits independently. Often a family member engaged in caregiving responsibilities assists with such healthcare tasks [6] highlighting the relevance of including caregivers in studies on outpatient medical follow-up post-stroke. Evidence suggests that caregivers' involvement in care plans of their care recipients and providing adequate education to the caregivers can decrease costs and increase patient satisfaction [7].

A systematic review involving 168 stroke survivors and 328 informal caregivers synthesized findings from 51 qualitative studies exploring primary care and community services experiences. They reported stroke survivor-caregiver dyads feeling marginalized by inadequate information provision, limited continuity of care and access to services post-stroke. None of the studies were from an Asian setting and the scope of the review excluded quantitative studies, which may provide more generalizable findings [8]. A cross-sectional study in Canada comparing healthcare visits of patients with and without stroke reported patients with stroke were twice more likely to visit a medical specialist and 1.5 times more likely to visit a family physician as compared to patients without stroke. Although researchers explored the association of outpatient medical healthcare visits with stroke survivors' demographics, mobility, comorbid cardiometabolic conditions, and $\operatorname{mood} /$ anxiety disorders, they did not examine the association with any caregiver factor in their study [5]. Roth and colleagues used Medicare claims data to study health service utilization over six months after index stroke hospitalization in 279 stroke survivors from the REGARDS (REasons for Geographic And Racial Differences in Stroke) study in the US. They reported that co-residing with a caregiver was associated with reduced health service utilization, including shorter hospital lengths of stay, fewer emergency department visits, and fewer primary care visits [9]. Another study in the US exploring the contribution of caregiver factors in healthcare service utilization by stroke survivors reported caregiver's health beliefs being associated with stroke survivors attending scheduled medical and therapy appointments post-discharge from inpatient rehabilitation facilities [10]. Among these existing studies exploring the role of caregivers in outpatient medical follow-up, most of the studies are either qualitative [8] or conducted in Western settings $[5,9,10]$ and had limited $[9,10]$ or no inclusion of caregiver factors [5]. Addressing the existing gaps, we aimed to examine the association of caregiver factors (along with patient factors) with outpatient medical follow-up of stroke survivors over 1-year post-stroke. The outpatient medical follow-up comprised of PC and SOC visits. PC visits consisted of stroke survivor's visits to any public PC clinics in Singapore during the yearlong follow-up. Also known as "one stop primary care clinics," public PC clinics are government run, providing subsidized care to Singaporeans and permanent residents. They are multi-doctor led clinics, which provide a comprehensive range of services [11]. While the Singapore healthcare system consists of a mixed public-private primary care, almost half (45\%) of patients with chronic diseases are managed in public PC clinics [12]. SOC visits included attendance to any of the specialist run outpatient clinics in the tertiary hospital premises.

\section{Methods}

We conducted a yearlong, prospective, observational study involving stroke survivors and their caregivers recruited from all five tertiary hospitals in Singapore during the recruitment period, from December 2010 to September 2013. The eligibility criteria for stroke survivors included the following: (a) Singaporean or permanent resident, more than 40 years old and residing in Singapore for the next one year, (b) stroke must be a recent diagnosis (i.e., stroke symptoms occurring within fourweeks before admission) with the diagnosis made by a clinician and/or supported by brain imaging (CT or MRI) and (c) not globally aphasic. The eligibility criteria for the caregivers included the following: (a) an immediate or extended family member or friend, (b) more than 21 years of age (the legal definition of adult in Singapore), (c) providing care or assistance of any kind and 
taking responsibility for the patient (as recognized by the patient) and (d) not fully paid for caregiving. We did not impose any language related exclusions, enabling us to recruit a multi-ethnic study cohort. The study procedures are reported in detail separately $[13,14]$. This study was approved by the National University of Singapore Institutional Review Board, SingHealth Centralized Institutional Review Board, and the National Health Group Domain Specific Review Board. Written informed consent was obtained from both the patients and the caregivers in their preferred language by trained researchers. All methods were performed in accordance with the guidance provided in the Declaration of Helsinki.

\section{Data collection}

We administered face-to-face verbal questionnaires to both stroke survivors and caregivers at baseline, 3 -month and 12-month time points. Only caregivers were administered verbal questionnaires via telephone at 6-month and 9-month time points. The data collected in these surveys were broadly categorized under the health, social, and financial domains, each comprising patient, caregiver, and self-reported healthcare utilization variables, respectively $[14,15]$. The main difference between face-to-face and telephone surveys was capturing all three domains during face-to-face surveys, while only financial domain data was captured during telephone surveys. We extracted the dependent variables from the National Claims Database, which has been reported to be a more objective source of healthcare data [16]. The National Claims Database is a nationwide database of healthcare utilization and associated expenditure maintained centrally by the Ministry of Health in Singapore. With the aid of a unique identification number allocated to all Singapore citizens and permanent residents, we linked our prospective cohort data with the healthcare data in the National Claims Database achieving a match rate of more than $95 \%$. The independent variables were taken from the baseline and 3-month face-to-face verbal questionnaires of our observational study (i.e., patient variables at baseline and caregiver variables at 3-month).

\section{Dependent variables}

The primary outcome variable was counts of PC visits and SOC visits within the first three months post-stroke (i.e., early post-stroke period or $0-3$ months). In addition, we separately examined PC and SOC visits 4-12 months post-stroke or late post-stroke period. PC visits consisted of stroke survivor's visits to any public PC clinics in Singapore during the yearlong follow-up. For current analysis, we did not include home visiting services by family physicians or general practitioners.

\section{Independent variables}

Our primary independent variables were caregiver factors assessed at 3 months post index stroke admission: socio-demographic variables, caregiver relationship, comorbid conditions, co-residing with the care recipient (i.e., whether the caregiver lived with the stroke survivor in the same house), caregiver-reported patient behavioral problems, caregiver burden, family conflict, social support and caregiver-adopted care management strategies. We used the revised dementia management strategies scale to capture caregiver-adopted care management strategies. The 20-item instrument version has been validated in Singapore [17] and records responses to the frequency of adopted strategy on a 5 -point Likert scale: $1=$ never, $2=$ seldom, $3=$ sometimes, $4=$ often and $5=$ most of the time. The instrument comprises two subscales of positive and negative dimensions, with good reported internal consistency in the Singapore population (Cronbach's alpha 0.89 and 0.87 respectively) [17]. We summated the total score across these two dimensions of positive and negative care management strategies. An example of a statement under positive care management strategy was, "I made it a point to praise him when he did what I considered appropriate." An example of a statement under the negative care management strategy was, "I yelled or acted angry, it was often the only way to get my way with him."

We considered the following patient variables collected at baseline: socio-demographic variables, marital status, ward class, comorbid condition (captured using Charlson Comorbidity Index, CCI) [18], stroke type (ischemic or non-ischemic including hemorrhagic and mixed); recurrent stroke, stroke severity (measured using National Institute of Health Scale, NIHSS) [19], level of disability (measured using Modified Rankin Scale, mRS) [20], cognitive impairment (using the Mini-Mental State Examination, MMSE) [21] and discharge destination. For scales with significant ( $>10)$ number of missing cases (NIHSS, MMSE, Revised memory and behavior checklist), we used the person mean substitution approach to impute for missing values for cases with less than half the constituent items missing [22]. Please refer to Additional file 1 for detailed description of independent variables included in the study.

\section{Data analysis}

Univariate analysis was performed to describe our sample of stroke patient-caregiver dyads. Bivariate analysis was performed using Poisson modelling to examine the associations between caregiver/patient factors and the risk of $\mathrm{PC} / \mathrm{SOC}$ visits post-stroke. Independent variables 
(caregiver and patient factors) having $p$-value $<0.1$ in the bivariate analyses were chosen as potential predictors for the multivariable Poisson regression model. Using these potential predictors, a backward variable selection approach was conducted to identify the most parsimonious model by removing the least significant variable at each model building iteration step with a p-value for inclusion $<0.05$ (except for age, gender, ethnicity and ward class of the patient with stroke which we opted to retain in the model a priori to standardize for sociodemographic variables). With the most parsimonious adjusted model, we assessed for over-dispersion and excessive zeroes using alpha statistic and Voung test, respectively $[23,24]$ and applied the appropriate regression model accordingly. We reported the unadjusted and adjusted incidence rate ratio (IRR) estimates with 95\% confidence intervals (CI). Separate models were run for PC visits and SOC visits for the following two time periods: first 3 months post-stroke and subsequent 4-12 months post-stroke. Results are reported based on a significance level set at 5\%. All analysis was performed in Stata version 14.1 [25].

\section{Results}

Two hundred and fifty-six stroke survivor and caregiver dyads were available for the current analysis. (please refer to Fig. 1). The average (standard deviation or SD) number of PC visits for stroke survivors over $0-3$ months and 4-12 months post-stroke were 0.867 (1.197) and 2.305 (2.242), respectively. The average (SD) number of SOC visits for stroke survivors over $0-3$ months and 4-12 months post-stroke were 1.836 (1.823) and 4.605 (5.616), respectively. The average age of caregivers was 50 years, with $76 \%$ female, $57 \%$ Chinese and $79 \%$ married. With the mean age of 61.8 years, the majority of the stroke survivors were male (64\%), Chinese $(58 \%)$ and married (80\%). Eighty-nine percent of the stroke survivors had an ischemic stroke, with $25 \%$ discharged to a step-down facility from an acute hospital setting (please refer to Table 1).

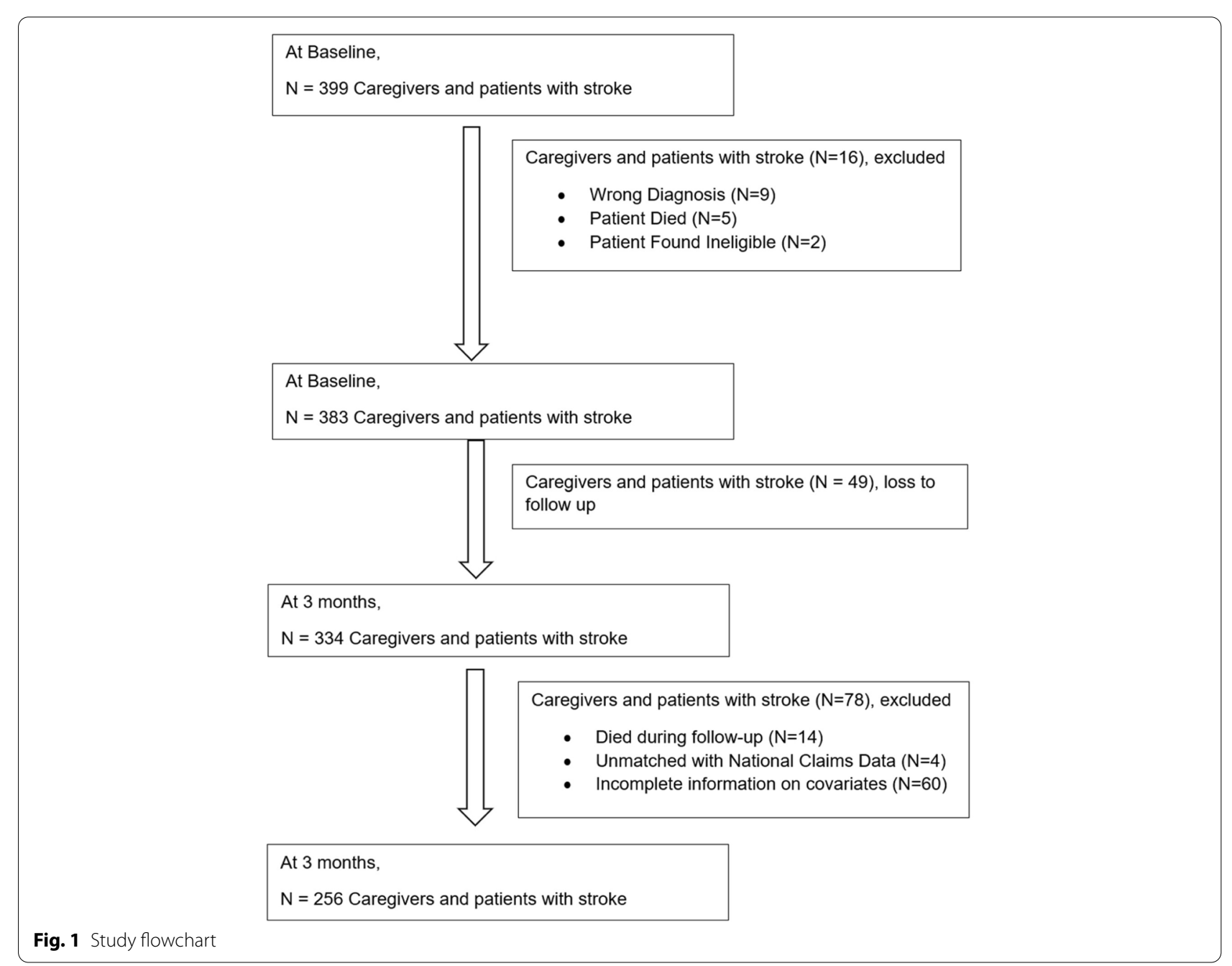


Table 1 Descriptive characteristics of caregivers and patients

\begin{tabular}{|c|c|c|}
\hline & No. (\%) unless & \\
\hline \multicolumn{3}{|l|}{ Caregiver ${ }^{\text {f factors }}$} \\
\hline Age (in years) & Mean (SD) & $50.0(13.2)$ \\
\hline \multirow[t]{2}{*}{ Gender } & Male & $61(24)$ \\
\hline & Female & $195(76)$ \\
\hline \multirow[t]{2}{*}{ Ethnicity } & Chinese & $147(57)$ \\
\hline & Non-Chinese & $109(43)$ \\
\hline \multirow[t]{2}{*}{ Marital status } & Married & 201(79) \\
\hline & Single & $55(21)$ \\
\hline \multirow[t]{4}{*}{ Caregiver relationship } & Spouse & $155(60)$ \\
\hline & Adult-Child & $74(29)$ \\
\hline & Sibling & $10(4)$ \\
\hline & Others & $17(7)$ \\
\hline \multirow[t]{4}{*}{ Comorbid conditions } & None & $153(60)$ \\
\hline & 1 & $57(22)$ \\
\hline & 2 & $24(9)$ \\
\hline & $\geq 3$ & $22(9)$ \\
\hline \multirow[t]{2}{*}{ Co-residing with patient } & Yes & $227(89)$ \\
\hline & No & $29(11)$ \\
\hline \multirow[t]{2}{*}{ Caring for multiple care recipients } & Yes & $106(41)$ \\
\hline & No & $150(59)$ \\
\hline \multicolumn{3}{|l|}{ Revised memory and behavior checklist } \\
\hline Memory problems & Mean (SD) & $5.1(6.0)$ \\
\hline Depressive behavior problems & Mean (SD) & $3.2(4.9)$ \\
\hline Disruptive behavior problems & Mean (SD) & $2.7(3.6)$ \\
\hline \multicolumn{3}{|l|}{ Caregiver burden } \\
\hline Oberst caregiving burden scale & Mean (SD) & $31.8(12.7)$ \\
\hline Zarit burden interview & Mean (SD) & $8.8(7.9)$ \\
\hline \multicolumn{3}{|l|}{ Family conflict } \\
\hline Attitude towards patient & Mean (SD) & $11.4(4.5)$ \\
\hline Attitude towards caregiver & Mean (SD) & $11.6(4.4)$ \\
\hline \multicolumn{3}{|l|}{ Social support (instrumental) } \\
\hline \multirow[t]{2}{*}{ FDW for general help } & Yes & $208(81)$ \\
\hline & No & $48(19)$ \\
\hline \multirow[t]{2}{*}{ FDW for stroke patient } & Yes & $33(13)$ \\
\hline & No & $223(87)$ \\
\hline Social support (perceived) & Mean (SD) & $26.4(4.9)$ \\
\hline \multicolumn{3}{|l|}{ Care management strategies } \\
\hline Positive strategies & Mean (SD) & $34.5(10.8)$ \\
\hline Negative strategies & Mean (SD) & $11.1(4.6)$ \\
\hline \multicolumn{3}{|l|}{ Patient ${ }^{b}$ factors } \\
\hline Age (in years) & Mean (SD) & $61.8(10.5)$ \\
\hline \multirow[t]{2}{*}{ Gender } & Male & $165(64)$ \\
\hline & Female & $91(36)$ \\
\hline \multirow[t]{2}{*}{ Ethnicity } & Chinese & $149(58)$ \\
\hline & Non-Chinese & $107(42)$ \\
\hline \multirow[t]{2}{*}{ Marital status } & Married & $206(80)$ \\
\hline & Single & $50(20)$ \\
\hline \multirow[t]{2}{*}{ Ward class } & Unsubsidized & $21(8)$ \\
\hline & Subsidized & $235(92)$ \\
\hline
\end{tabular}


Table 1 (continued)

\begin{tabular}{lll}
\hline & No. (\%) unless otherwise stated & $52(20)$ \\
\hline Charlson Comorbidity Index (during stroke onset) & $1-3$ & $162(64)$ \\
& $4-6$ & $42(16)$ \\
Stroke type & Ischemic & $227(89)$ \\
Recurrent stroke & Non-ischemic & $29(11)$ \\
National Institute of Health Scale & Yes & $42(16)$ \\
& No & $214(84)$ \\
Modified rankin scale & Mild (0-4) & $145(57)$ \\
Mini-mental state examination & Moderately severe (5-14) & $97(38)$ \\
& Severe (15-24) & $14(5)$ \\
Discharge to community hospital or step-down facility & No or slight disability (0-2) & $105(41)$ \\
Centre for epidemiological studies depression scale & Moderate or severe disability (3-5) & $151(59)$ \\
\hline
\end{tabular}

Source: Tyagi S, Koh GCH, Luo N, Tan KB, Hoenig H, Matchar DB, et al. Dyadic approach to post-stroke hospitalizations: role of caregiver and patient characteristics. BMC Neurology. 2019;19(1):267

Abbreviations: No. number, SD standard deviation, FDW foreign domestic worker

${ }^{a}$ Variables collected at 3-month time point

${ }^{b}$ Variables collected at baseline

\section{Outpatient medical (PC) healthcare utilization}

Table 2 depicts the results of the association of caregiver and patient characteristics with the rate of PC visits across three months post-stroke. The variables that entered the final adjusted model of PC visits were caregiver-reported patient behavioral problems (memory), objective caregiver burden measured on the Oberst caregiving burden scale and stroke type. For every 1 unit increase in caregiver-reported patient memory problem score, the expected rate ratio of $\mathrm{PC}$ visits decreased by a factor of 0.954 (95\% CI: 0.919, 0.990). With every 1 unit increase in the Oberst caregiver burden scale score, the rate ratio of PC visits decreased by a factor of 0.976 (95\% CI: 0.959, 0.993). The variables that entered the final adjusted model of PC visits over 4-12 months were only patient factors, specifically, CCI, stroke type and stroke severity. (Please refer to Table 3) Compared to stroke survivors with CCI score of $1-3$, the rate ratio of PC visits over 4-12 months post-stroke was 1.655 (95\% CI: $1.152,2.378)$ times higher in those with CCI score of 4-6. Compared to those with non-ischemic stroke, the rate ratio of PC visits over 4-12 months post-stroke was 1.867 (95\% CI:1.137, 3.066) times higher. Stroke survivors with moderately severe (IRR: 0.649; 95\% CI: 0.490, 0.859) stroke were less likely to have PC visits over 4-12 months post-stroke as compared to those with mild stroke.

\section{Outpatient medical (SOC) healthcare utilization}

Table 4 depicts the results of the association of caregiver characteristics with the rate of SOC visits across three months post-stroke. None of the caregiver or patient variables entered the final adjusted model of SOC visits over three months post-stroke. The variables that entered the final adjusted model of SOC visits over 4-12 months post-stroke were co-residing caregiver, negative care management strategies, functional status and discharge destination post-stroke. (Please refer to Table 5) Compared to those with no co-residing caregiver, those with co-residing caregivers had almost 1.6 times greater rate of SOC visits over 4-12 months post-stroke (IRR: 1.576; $95 \%$ CI: 1.040, 2.389). With every 1 unit increase in negative care management strategy score, the rate ratio of SOC visits increased by a factor of 1.033 (95\% CI: 1.005, 1.061). Compared to those with no or mild disability, those with moderate to severe disabilities had 1.564 times greater rate of SOC visits over 4-12 months post-stroke 
Table 2 Association of caregiver and patient characteristics with outpatient medical follow-up (primary care) 0-3 months post-stroke

\begin{tabular}{|c|c|c|c|c|c|}
\hline \multirow[t]{2}{*}{ Variable } & \multirow[t]{2}{*}{ Reference category } & \multicolumn{4}{|c|}{ Primary care visits ( 0 - 3 months) } \\
\hline & & IRR (95\% Cl) & $P$-value & $\operatorname{aIRR}^{\mathrm{a}}(95 \% \mathrm{Cl})$ & $P$-value \\
\hline \multicolumn{6}{|l|}{ Caregiver factors } \\
\hline Age (in years) & & $1.013(1.002,1.023)$ & 0.017 & & \\
\hline Gender & Male & $0.845(0.628,1.136)$ & 0.264 & & \\
\hline Ethnicity & Non-Chinese & $1.195(0.912,1.567)$ & 0.197 & & \\
\hline Marital status & Single & $0.917(0.671,1.254)$ & 0.589 & & \\
\hline Caregiver relationship & Spouse & & 0.443 & & \\
\hline Adult-child & & $0.809(0.594,1.101)$ & & & \\
\hline Sibling & & $0.641(0.283,1.451)$ & & & \\
\hline Others & & $0.943(0.554,1.605)$ & & & \\
\hline Comorbid conditions & None & & 0.829 & & \\
\hline 1 & & $0.856(0.610,1.202)$ & & & \\
\hline 2 & & $0.924(0.578,1.477)$ & & & \\
\hline$\geq 3$ & & $1.008(0.631,1.611)$ & & & \\
\hline Co-residing with patient & No & $1.290(0.815,2.043)$ & 0.277 & & \\
\hline Caring for multiple care recipients & No & $0.947(0.724,1.238)$ & 0.691 & & \\
\hline \multicolumn{6}{|l|}{ Revised memory and behavior checklist } \\
\hline Memory problems & & $0.937(0.910,0.965)$ & $<0.001$ & $0.954(0.919,0.990)$ & 0.013 \\
\hline Depressive behavior problems & & $0.959(0.927,0.992)$ & 0.015 & & \\
\hline Disruptive behavior problems & & $0.981(0.943,1.020)$ & 0.333 & & \\
\hline \multicolumn{6}{|l|}{ Caregiver burden } \\
\hline Oberst caregiving burden scale & & $0.972(0.960,0.984)$ & $<0.001$ & $0.976(0.959,0.993)$ & 0.005 \\
\hline Zarit burden interview & & $0.994(0.977,1.012)$ & 0.523 & & \\
\hline \multicolumn{6}{|l|}{ Family conflict } \\
\hline Attitude towards patient & & $0.971(0.943,0.999)$ & 0.041 & & \\
\hline Attitude towards caregiver & & $0.966(0.938,0.995)$ & 0.021 & & \\
\hline \multicolumn{6}{|l|}{ Social support (instrumental) } \\
\hline FDW for general help & No & $1.599(1.076,2.376)$ & 0.020 & & \\
\hline FDW for stroke patient & No & $0.455(0.265,0.781)$ & 0.004 & & \\
\hline Social support (perceived) & & $1.011(0.984,1.039)$ & 0.427 & & \\
\hline \multicolumn{6}{|l|}{ Care management strategies } \\
\hline Positive strategies & & $0.981(0.969,0.993)$ & 0.002 & & \\
\hline Negative strategies & & $0.995(0.966,1.024)$ & 0.737 & & \\
\hline \multicolumn{6}{|l|}{ Patient factors } \\
\hline Age (in years) & & $1.001(0.989,1.014)$ & 0.827 & & \\
\hline Gender & Male & $0.853(0.643,1.130)$ & 0.268 & & \\
\hline Ethnicity & Non-Chinese & $1.094(0.836,1.431)$ & 0.515 & & \\
\hline Marital status & Single & $1.254(0.878,1.792)$ & 0.214 & & \\
\hline Ward class & Unsubsidized & $1.437(0.820,2.516)$ & 0.205 & & \\
\hline $\mathrm{CCl}$ & $1-3$ & & 0.593 & & \\
\hline $4-6$ & & $1.202(0.844,1.711)$ & & & \\
\hline$>=7$ & & $1.175(0.749,1.842)$ & & & \\
\hline Stroke type & Non-ischemic & $2.451(1.337,4.493)$ & 0.004 & $2.327(1.110,4.876)$ & 0.025 \\
\hline Recurrent stroke & No & $0.827(0.566,1.209)$ & 0.327 & & \\
\hline National Institute of Health Scale & Mild (0-4) & & $<0.001$ & & \\
\hline Moderately severe (5-14) & & $0.594(0.443,0.797)$ & & & \\
\hline Severe (15-24) & & $0.266(0.098,0.716)$ & & & \\
\hline Modified rankin scale & No or slight disability (0-2) & & & & \\
\hline Moderate or severe disability (3-5) & & $0.602(0.462,0.784)$ & $<0.001$ & & \\
\hline
\end{tabular}


Table 2 (continued)

\begin{tabular}{|c|c|c|c|c|c|}
\hline \multirow[t]{2}{*}{ Variable } & \multirow[t]{2}{*}{ Reference category } & \multicolumn{4}{|c|}{ Primary care visits (0 - 3 months) } \\
\hline & & IRR $(95 \% \mathrm{CI})$ & $P$-value & $\operatorname{aIRR}^{\mathrm{a}}(95 \% \mathrm{Cl})$ & $P$-value \\
\hline Mini-mental state examination & No cognitive impairment (24-30) & & $<0.001$ & & \\
\hline Mild cognitive impairment (18-23) & & $0.696(0.503,0.965)$ & & & \\
\hline Severe cognitive impairment (1-17) & & $0.422(0.265,0.671)$ & & & \\
\hline Discharge to community hospital & No & $0.569(0.398,0.813)$ & 0.002 & & \\
\hline $\begin{array}{l}\text { Centre for epidemiological studies } \\
\text { depression scale }\end{array}$ & & $1.008(0.985,1.032)$ & 0.495 & & \\
\hline
\end{tabular}

Abbreviations: IRR incidence rate ratio, alRR adjusted incidence rate ratio, $C l$ confidence interval, FDW foreign domestic worker

${ }^{a}$ Model adjusted for age, gender, ethnicity and ward class of the patient

(95\% CI: 1.197, 2.043). Being discharged to community hospital after the index stroke was associated with a higher rate of SOC visits in 4-12 months post-stroke.

\section{Discussion}

We are among the first to describe the role of caregivers in outpatient medical follow-up post-stroke. Adding new knowledge to existing literature, we demonstrated that the association of caregiver factors with outpatient medical visits varied by the type of service consumed (i.e., $\mathrm{PC}$ versus $\mathrm{SOC}$ ) and temporally across the early and late post-stroke period within each service. We found that caregiver factors were significantly associated with PC visits in the early post-stroke period only, with patient factors being significantly associated with early and late post-stroke periods. A possible explanation could be related to the caregivers stepping into the new caregiving role during the early period, which is often reported as a challenging and overwhelming experience [15, 26, 27]. Once caregivers transition into a stable phase with role familiarity, it may be possible that clinical factors solely determined the frequency of $\mathrm{PC}$ visits.

We reported a higher mean number of SOC visits than PC visits for both $0-3$ months and 4-12 months post-stroke. Contrary to our finding, previous studies have reported stroke survivors to have higher primary care visits as compared to specialist visits over 1 month [28], 3 months [29] and 12 months [5] poststroke. It may be possible that stroke survivors in our setting continued being treated in SOC clinics without timely transfer to PC clinics. It is well-established that specialist settings encounter high patient load within Singapore, which may be transferred to primary care setting, ensuring the right care in the right setting. This preposition of treating patients in the most appropriate setting at the lowest possible cost and achieving favourable patient outcomes is known as "right-siting" of healthcare services. This term has been commonly used in Singapore since 2004 to describe the principle of transferring patients with stable chronic conditions from SOC clinics to PC clinics [30]. While such "rightsiting" programs have been established for patients with chronic kidney disease [31], asthma [32] and diabetes [30] there has been no such program for stroke survivors. Another possibility explaining the difference in our finding with existing literature could be related to differences in patient profiles; specifically, stroke survivors in our study may require specialist care for poststroke needs. Further exploration of the transition between SOC and PC settings post-stroke is beyond the scope of the current study, which aimed to study the caregiver and patient factors associated with the use of PC and SOC services. However, acknowledging the importance of treating patients in the most appropriate care setting, future research should examine transitions across different outpatient medical care settings to optimize the use of such outpatient services.

While there is unequivocal evidence in both nonstroke [33, 34] and stroke populations [13, 35] of caregiver burden being associated with the increased use of inpatient services, the role of caregiver burden in the use of outpatient clinical services is unexplored and unestablished. Within the stroke population, caregiver burden is reported to be associated with increased hospitalization [13] and increased institutionalization of stroke survivors [35]. Contrary to the established association of caregiver burden with the increased use of inpatient services, we found that caregiver burden was associated with reduced PC visits post-stroke. Our finding is concordant with previous literature on the utilization of non-urgent services being associated with caregiver burden [36]. Considering the role of caregiver burden in post-stroke inpatient and PC services utilization, it may be possible that burdened caregivers do not engage in outpatient medical follow-up in the early period, which may result in subsequent greater hospitalizations, further highlighting the importance of early outpatient medical follow-up. 
Table 3 Association of caregiver and patient characteristics with outpatient medical follow-up (primary care) 4-12 months poststroke

\begin{tabular}{|c|c|c|c|c|c|}
\hline \multirow[t]{2}{*}{ Variable } & \multirow[t]{2}{*}{ Reference category } & \multicolumn{4}{|c|}{ Primary care visits ( 4 - 12 months) } \\
\hline & & IRR (95\% CI) & $P$-value & $\operatorname{alRR}^{\mathrm{a}}(95 \% \mathrm{Cl})$ & $P$-value \\
\hline \multicolumn{6}{|l|}{ Caregiver factors } \\
\hline Age (in years) & & $1.005(0.999,1.011)$ & 0.127 & & \\
\hline Gender & Male & $0.978(0.810,1.180)$ & 0.816 & & \\
\hline Ethnicity & Non-Chinese & $0.981(0.833,1.154)$ & 0.816 & & \\
\hline Marital status & Single & $1.050(0.860,1.281)$ & 0.633 & & \\
\hline Caregiver relationship & Spouse & & 0.115 & & \\
\hline Adult-child & & $0.989(0.823,1.187)$ & & & \\
\hline Sibling & & $0.606(0.355,1.034)$ & & & \\
\hline Others & & $1.248(0.926,1.682)$ & & & \\
\hline Comorbid conditions & None & & 0.418 & & \\
\hline 1 & & $1.124(0.925,1.365)$ & & & \\
\hline 2 & & $1.093(0.830,1.441)$ & & & \\
\hline$\geq 3$ & & $0.869(0.633,1.194)$ & & & \\
\hline Co-residing with patient & No & $1.218(0.925,1.604)$ & 0.160 & & \\
\hline Caring for multiple care recipients & No & $0.998(0.847,1.176)$ & 0.980 & & \\
\hline \multicolumn{6}{|l|}{ Revised memory and behavior checklist } \\
\hline Memory problems & & $0.988(0.974,1.003)$ & 0.108 & & \\
\hline Depressive behavior problems & & $0.980(0.962,0.999)$ & 0.035 & & \\
\hline Disruptive behavior problems & & $0.996(0.974,1.019)$ & 0.714 & & \\
\hline \multicolumn{6}{|l|}{ Caregiver burden } \\
\hline Oberst caregiving burden scale & & $0.989(0.982,0.995)$ & 0.001 & & \\
\hline Zarit burden interview & & $0.994(0.983,1.004)$ & 0.232 & & \\
\hline \multicolumn{6}{|l|}{ Family conflict } \\
\hline Attitude towards patient & & $0.978(0.961,0.995)$ & 0.013 & & \\
\hline Attitude towards caregiver & & $0.987(0.970,1.006)$ & 0.173 & & \\
\hline \multicolumn{6}{|l|}{ Social support (instrumental) } \\
\hline FDW for general help & No & $1.233(0.988,1.539)$ & 0.064 & & \\
\hline FDW for stroke patient & No & $0.681(0.515,0.901)$ & 0.007 & & \\
\hline Social support (perceived) & & $1.000(0.984,1.017)$ & 0.987 & & \\
\hline \multicolumn{6}{|l|}{ Care management strategies } \\
\hline Positive strategies & & $0.996(0.989,1.004)$ & 0.332 & & \\
\hline Negative strategies & & $0.995(0.978,1.013)$ & 0.600 & & \\
\hline \multicolumn{6}{|l|}{ Patient factors } \\
\hline Age (in years) & & $0.998(0.991,1.006)$ & 0.686 & & \\
\hline Gender & Male & $0.828(0.696,0.986)$ & 0.034 & & \\
\hline Ethnicity & Non-Chinese & $0.899(0.764,1.058)$ & 0.199 & & \\
\hline Marital status & Single & $1.148(0.928,1.419)$ & 0.204 & & \\
\hline Ward class & Unsubsidized & $1.137(0.833,1.551)$ & 0.418 & & \\
\hline $\mathrm{CCl}$ & $1-3$ & & 0.002 & & 0.023 \\
\hline $4-6$ & & $1.526(1.207,1.928)$ & & $1.655(1.152,2.378)$ & \\
\hline$>=7$ & & $1.471(1.102,1.963)$ & & $1.590(0.999,2.527)$ & \\
\hline Stroke type & Non-ischemic & $1.805(1.304,2.497)$ & $<0.001$ & $1.867(1.137,3.066)$ & 0.014 \\
\hline Recurrent stroke & No & $0.893(0.712,1.120)$ & 0.328 & & \\
\hline National Institute of Health Scale & Mild (0-4) & & $<0.001$ & & 0.010 \\
\hline Moderately severe (5-14) & & $0.686(0.575,0.819)$ & & $0.649(0.490,0.859)$ & \\
\hline Severe (15-24) & & $0.558(0.360,0.865)$ & & $0.813(0.414,1.596)$ & \\
\hline Modified rankin scale & No or slight disability (0-2) & & & & \\
\hline
\end{tabular}


Table 3 (continued)

\begin{tabular}{|c|c|c|c|c|c|}
\hline \multirow[t]{2}{*}{ Variable } & \multirow[t]{2}{*}{ Reference category } & \multicolumn{4}{|c|}{ Primary care visits (4 - 12 months) } \\
\hline & & IRR (95\% CI) & $P$-value & $\operatorname{aIRR}^{\mathrm{a}}(95 \% \mathrm{Cl})$ & $P$-value \\
\hline Moderate or severe disability (3-5) & & $0.724(0.616,0.851)$ & $<0.001$ & & \\
\hline Mini-mental state examination & No cognitive impairment (24-30) & & 0.003 & & \\
\hline Mild cognitive impairment (18-23) & & $1.086(0.903,1.307)$ & & & \\
\hline Severe cognitive impairment (1-17) & & $0.679(0.528,0.874)$ & & & \\
\hline Discharge to community hospital & No & $0.766(0.628,0.935)$ & 0.009 & & \\
\hline $\begin{array}{l}\text { Centre for epidemiological studies } \\
\text { depression scale }\end{array}$ & & $1.006(0.992,1.021)$ & 0.387 & & \\
\hline
\end{tabular}

Abbreviations: IRR incidence rate ratio, alRR adjusted incidence rate ratio, $\mathrm{Cl}$ confidence interval, FDW foreign domestic worker

${ }^{a}$ Model adjusted for age, gender, ethnicity and ward class of the patient

We found caregiver-reported memory type of behavioral problems were associated with decreased PC visits. One possible explanation could be caregivers perceiving stroke survivors' memory problems as part of normal ageing and not cues to seek medical care for post-stroke sequelae [37-39]. Alternatively, handling memory-related behavioral issues may additionally strain the caregivers and they may not have the bandwidth or time to seek PC services. A study comparing healthcare utilization in stroke and non-stroke populations in the Canadian setting reported stroke survivors to have significantly more visits to most healthcare professionals than those without stroke. Further, researchers reported that stroke survivors with mood or anxiety disorders were 1.4 times more likely to visit a family physician than those without these disorders [5]. Differences in findings across both studies could be related to the different types of behavioral issues captured in the analyses (i.e., memory vs mood disorders), differences in data collection methods (i.e., objective source of PC visits from claims records in our study versus self-reported PC visits in the comparison study) or differences in the perception of behavioral problems.

Our findings related to patient determinants of PC visits were in concordance with previous literature, specifically patients with multiple chronic conditions being high utilizers of healthcare services post-stroke compared to those without such chronic conditions [10, 31]. In agreement with our results were the results reported by Roth and colleagues [9], with a higher Charlson comorbidity score being associated with higher consumption of health services. Specifically, stroke survivors with higher scores had longer hospitalization stay, more primary care outpatient visits and increased odds of receiving rehabilitation services.

For SOC visits, we found having a co-residing caregiver associated with increased SOC visits in the late post-stroke period, which is in agreement with the findings from a non-stroke population [40]. While there is consistent evidence supporting the presence of a coresiding caregiver being associated with reduced use of inpatient services $[9,41,42]$, such evidence is limited for outpatient medical services. A US-based study on community-dwelling, Medicare enrolled, hospitalized patients explored the association of living alone (without a potential caregiver) with readmission within 2 months post-discharge. They reported the odds of early readmission being 1.5 times in those living alone versus those living with someone [41]. Skinner and colleagues reported the co-residing status of adult-child caregivers being associated with reduced hospital length of stay as compared to those with adult-child caregivers living more than 15 min away from the elderly [42]. Within the stroke population, having a co-residing caregiver was reported to be associated with reduced length of hospitalization and fewer ED visits [9]. It is possible that having a co-residing caregiver ensures availability of support or assistance in the community post-stroke, which may aid in a smooth transition to home, prevent unnecessary use of acute healthcare services and facilitate adherence and attendance to scheduled specialist appointments.

Caregivers' negative care management strategies were associated with increased SOC visits in the late poststroke period. This could be explained by the caregivers' perception of SOC settings and specialists. Past studies have reported a differential preference for specialists over regular doctors for specific conditions [43]. Additionally, caregivers may feel more comfortable sharing their problems during a SOC visit as compared to $\mathrm{PC}$ visit since the latter tend to be shorter, with about $89 \%$ of PC consults for chronic ailments in Singapore lasting between 6 to 10 min [44]. A third possibility could be that stroke survivors using SOC services may have higher care needs, making caregiving challenging, resulting in caregivers adopting more negative care management strategies. Qualitatively exploring the caregiving challenges in caregivers of stroke survivors visiting SOC and PC clinics may help gain a deeper understanding of this reported 
Table 4 Association of caregiver and patient characteristics with outpatient medical follow-up (specialist outpatient care) 0-3 months post-stroke

\begin{tabular}{|c|c|c|c|c|c|}
\hline \multirow[t]{2}{*}{ Variable } & \multirow[t]{2}{*}{ Reference category } & \multicolumn{4}{|c|}{ SOC Visits (0 - 3 months) } \\
\hline & & IRR (95\% CI) & $P$-value & $\operatorname{aIRR}^{\mathrm{a}}(95 \% \mathrm{Cl})$ & $P$-value \\
\hline \multicolumn{6}{|l|}{ Caregiver factors } \\
\hline Age (in years) & & $0.999(0.992,1.006)$ & 0.780 & & \\
\hline Gender & Male & $1.187(0.951,1.483)$ & 0.130 & & \\
\hline Ethnicity & Non-Chinese & $0.992(0.827,1.191)$ & 0.934 & & \\
\hline Marital status & Single & $0.975(0.784,1.213)$ & 0.820 & & \\
\hline Caregiver relationship & Spouse & & 0.380 & & \\
\hline Adult-child & & $0.959(0.782,1.175)$ & & & \\
\hline Sibling & & $0.946(0.588,1.522)$ & & & \\
\hline Others & & $0.680(0.441,1.049)$ & & & \\
\hline Comorbid conditions & None & & 0.857 & & \\
\hline 1 & & $1.021(0.818,1.274)$ & & & \\
\hline 2 & & $0.875(0.626,1.223)$ & & & \\
\hline$\geq 3$ & & $0.955(0.683,1.335)$ & & & \\
\hline Co-residing with patient & No & $1.269(0.927,1.736)$ & 0.137 & & \\
\hline Caring for multiple care recipients & No & $0.977(0.813,1.175)$ & 0.807 & & \\
\hline \multicolumn{6}{|l|}{ Revised memory and behavior checklist } \\
\hline Memory problems & & $1.005(0.990,1.020)$ & 0.486 & & \\
\hline Depressive behavior problems & & $1.018(1.001,1.036)$ & 0.040 & & \\
\hline Disruptive behavior problems & & $1.004(0.979,1.028)$ & 0.773 & & \\
\hline \multicolumn{6}{|l|}{ Caregiver burden } \\
\hline Oberst caregiving burden scale & & $1.004(0.997,1.011)$ & 0.308 & & \\
\hline Zarit burden interview & & $0.997(0.986,1.009)$ & 0.670 & & \\
\hline \multicolumn{6}{|l|}{ Family conflict } \\
\hline Attitude towards patient & & $1.011(0.991,1.032)$ & 0.295 & & \\
\hline Attitude towards caregiver & & $1.013(0.992,1.034)$ & 0.233 & & \\
\hline \multicolumn{6}{|l|}{ Social support (instrumental) } \\
\hline FDW for general help & No & $1.016(0.805,1.282)$ & 0.894 & & \\
\hline FDW for stroke patient & No & $1.085(0.835,1.409)$ & 0.544 & & \\
\hline Social support (perceived) & & $0.984(0.966,1.002)$ & 0.076 & & \\
\hline \multicolumn{6}{|l|}{ Care management strategies } \\
\hline Positive strategies & & $0.996(0.988,1.005)$ & 0.396 & & \\
\hline Negative strategies & & $1.008(0.988,1.027)$ & 0.443 & & \\
\hline \multicolumn{6}{|l|}{ Patient factors } \\
\hline Age (in years) & & $0.994(0.985,1.002)$ & 0.156 & & \\
\hline Gender & Male & $1.027(0.851,1.240)$ & 0.778 & & \\
\hline Ethnicity & Non-Chinese & $0.961(0.801,1.154)$ & 0.670 & & \\
\hline Marital status & Single & $1.011(0.804,1.271)$ & 0.926 & & \\
\hline Ward class & Unsubsidized & $1.111(0.787,1.567)$ & 0.550 & & \\
\hline $\mathrm{CCl}$ & $1-3$ & & 0.086 & & \\
\hline $4-6$ & & $1.137(0.891,1.451)$ & & & \\
\hline$>=7$ & & $1.387(1.032,1.865)$ & & & \\
\hline Stroke type & Non-ischemic & $0.796(0.613,1.034)$ & 0.088 & & \\
\hline Recurrent stroke & No & $1.308(1.045,1.637)$ & 0.019 & & \\
\hline National Institute of Health Scale & Mild (0-4) & & 0.021 & & \\
\hline Moderately severe (5-14) & & $0.779(0.639,0.948)$ & & & \\
\hline Severe (15-24) & & $1.151(0.799,1.658)$ & & & \\
\hline Modified rankin scale & No or slight disability (0-2) & & & & \\
\hline
\end{tabular}


Table 4 (continued)

\begin{tabular}{|c|c|c|c|c|c|}
\hline \multirow[t]{2}{*}{ Variable } & \multirow[t]{2}{*}{ Reference category } & \multicolumn{4}{|c|}{ SOC Visits (0 - 3 months) } \\
\hline & & IRR (95\% CI) & $P$-value & $\operatorname{aIRR}^{\mathrm{a}}(95 \% \mathrm{Cl})$ & $P$-value \\
\hline Moderate or severe disability (3-5) & & $1.081(0.898,1.301)$ & 0.411 & & \\
\hline Mini-mental state examination & No cognitive impairment (24-30) & & 0.756 & & \\
\hline Mild cognitive impairment (18-23) & & $1.034(0.835,1.280)$ & & & \\
\hline Severe cognitive impairment (1-17) & & $0.928(0.721,1.196)$ & & & \\
\hline Discharge to community hospital & No & $0.952(0.771,1.175)$ & 0.646 & & \\
\hline $\begin{array}{l}\text { Centre for epidemiological studies } \\
\text { depression scale }\end{array}$ & & $1.010(0.994,1.027)$ & 0.208 & & \\
\hline
\end{tabular}

Abbreviations: IRR incidence rate ratio, alRR adjusted incidence rate ratio, $C l$ confidence interval, FDW foreign domestic worker

${ }^{a}$ Model adjusted for age, gender, ethnicity and ward class of the patient

association. Similar to our findings, other researchers have reported stroke survivors' functional status playing a significant role in stroke-related costs $[45,46]$, and healthcare utilization [45, 47].

After establishing the role of caregivers in outpatient medical follow-up post-stroke, we recommend family physicians view caregivers not only as facilitators of care in the community but also as active members of the care team responsible for patient care and as potential clients requiring care and regular assessments. Viewing caregivers as clients during consults includes physicians assessing caregiver needs [48], coordinating required services and ensuring their well-being as part of the routine post-stroke followup. This will result in the stroke survivor-caregiver dyadic well-being and potentially ensure the sustainability of caregiving arrangement and continuity of outpatient medical follow-up. Having a caregiver as an active member of the care team can be operationalized by practicing the concept of "inclusive care" which establishes the caregiver role as "extending the healthcare team in the home environment and representing their care recipients in the clinic environment" [49].

\section{Study strengths}

We are the first to determine caregiver factors associated with outpatient medical follow-up post-stroke. The study recruitment extending to all the existing tertiary hospitals in Singapore during the recruitment period increases the representativeness of our findings. Furthermore, we had no language related exclusions, which increases the generalizability of our results. We had an objective source for the outcome measure (i.e., the National Claims Database), which increases the accuracy of data capture and limits the possibility of information bias. Moreover, not relying on participant follow-up to capture the outcome over time limits loss to follow-up bias. These, in turn, improve the internal validity of our study.

\section{Study limitations}

Our study has some limitations. Although we can comment on the directionality of association of caregiver factors with outpatient medical follow-up in the late post-stroke period, having captured the determinants before the outcome, we are limited to comment on the directionality of association of caregiver factors and outpatient medical follow-up in the early post-stroke period as both the determinants and outcomes were captured simultaneously. We excluded stroke survivors who died $(N=5)$ during the yearlong follow-up limiting the generalizability of our findings to patients who survive first year post-stroke.

\section{Conclusion}

In conclusion, we reported caregiver factors significantly associated with both PC and SOC visits, establishing caregivers' role in outpatient medical follow-up post-stroke. While caregiver-reported memory related behavioral problems of a stroke survivor and caregiver burden were significant associated with lower early post-stroke PC visits, co-residing caregiver and negative care management strategies were significantly associated with higher late post-stroke SOC visits. Our results support family-centered care provision by family physicians, viewing the caregivers not only as facilitators of care in the community but also as active members of the care team and as clients requiring care and regular assessments. Caregivers should be integrated into the care teams by practicing inclusive care, which also ensures the extension of the healthcare team in the home environment. 
Table 5 Association of caregiver and patient characteristics with outpatient medical follow-up (specialist outpatient care) 4-12 months post-stroke

\begin{tabular}{|c|c|c|c|c|c|}
\hline \multirow[t]{2}{*}{ Variable } & \multirow[t]{2}{*}{ Reference category } & \multicolumn{4}{|c|}{ SOC visits (4 - 12 months) } \\
\hline & & |RR (95\% CI) & $P$-value & $\operatorname{aIRR}^{\mathrm{a}}(95 \% \mathrm{Cl})$ & $P$-value \\
\hline \multicolumn{6}{|l|}{ Caregiver factors } \\
\hline Age (in years) & & $0.997(0.993,1.001)$ & 0.176 & & \\
\hline Gender & Male & $0.986(0.863,1.127)$ & 0.834 & & \\
\hline Ethnicity & Non-Chinese & $1.355(1.202,1.527)$ & 0.000 & & \\
\hline Marital status & Single & $1.007(0.876,1.157)$ & 0.927 & & \\
\hline Caregiver relationship & Spouse & & $<0.001$ & & \\
\hline Adult-child & & $1.257(1.110,1.423)$ & & & \\
\hline Sibling & & $1.282(0.974,1.688)$ & & & \\
\hline Others & & $0.823(0.632,1.071)$ & & & \\
\hline Comorbid conditions & None & & 0.966 & & \\
\hline 1 & & $0.983(0.853,1.133)$ & & & \\
\hline 2 & & $1.006(0.824,1.227)$ & & & \\
\hline$\geq 3$ & & $0.950(0.768,1.175)$ & & & \\
\hline Co-residing with patient & No & $1.254(1.030,1.527)$ & 0.024 & $1.576(1.040,2.389)$ & 0.032 \\
\hline Caring for multiple care recipients & No & $0.996(0.887,1.118)$ & 0.944 & & \\
\hline \multicolumn{6}{|l|}{ Revised memory and behavior checklist } \\
\hline Memory problems & & $1.011(1.002,1.021)$ & 0.016 & & \\
\hline Depressive behavior problems & & $1.013(1.002,1.025)$ & 0.018 & & \\
\hline Disruptive behavior problems & & $1.017(1.002,1.032)$ & 0.024 & & \\
\hline \multicolumn{6}{|l|}{ Caregiver burden } \\
\hline Oberst caregiving burden scale & & $1.017(1.013,1.022)$ & $<0.001$ & & \\
\hline Zarit burden interview & & $1.016(1.010,1.023)$ & $<0.001$ & & \\
\hline \multicolumn{6}{|l|}{ Family conflict } \\
\hline Attitude towards patient & & $0.983(0.971,0.995)$ & 0.007 & & \\
\hline Attitude towards caregiver & & $0.984(0.971,0.996)$ & 0.012 & & \\
\hline \multicolumn{6}{|l|}{ Social support (instrumental) } \\
\hline FDW for general help & No & $0.755(0.660,0.864)$ & $<0.001$ & & \\
\hline FDW for stroke patient & No & $1.414(1.216,1.644)$ & $<0.001$ & & \\
\hline Social support (perceived) & & $0.984(0.973,0.995)$ & 0.005 & & \\
\hline \multicolumn{6}{|l|}{ Care management strategies } \\
\hline Positive strategies & & $1.006(1.001,1.011)$ & 0.027 & & \\
\hline Negative strategies & & $1.035(1.024,1.046)$ & $<0.001$ & $1.033(1.005,1.061)$ & 0.021 \\
\hline \multicolumn{6}{|l|}{ Patient factors } \\
\hline Age (in years) & & $0.995(0.990,1.001)$ & 0.101 & & \\
\hline Gender & Male & $1.083(0.963,1.219)$ & 0.183 & & \\
\hline Ethnicity & Non-Chinese & $1.357(1.204,1.530)$ & $<0.001$ & & \\
\hline Marital status & Single & $0.862(0.751,0.990)$ & 0.035 & & \\
\hline Ward class & Unsubsidized & $0.975(0.794,1.198)$ & 0.808 & & \\
\hline $\mathrm{CCl}$ & $1-3$ & & $<0.001$ & & \\
\hline $4-6$ & & $1.175(1.004,1.375)$ & & & \\
\hline$>=7$ & & $1.601(1.330,1.927)$ & & & \\
\hline Stroke type & Non-ischemic & $0.904(0.760,1.075)$ & 0.253 & & \\
\hline Recurrent stroke & No & $1.175(1.015,1.361)$ & 0.030 & & \\
\hline National Institute of Health Scale & Mild (0-4) & & $<0.001$ & & \\
\hline Moderately severe (5-14) & & $1.237(1.098,1.392)$ & & & \\
\hline Severe (15-24) & & $1.359(1.075,1.718)$ & & & \\
\hline Modified rankin scale & No or slight disability (0-2) & & & & \\
\hline
\end{tabular}


Table 5 (continued)

\begin{tabular}{|c|c|c|c|c|c|}
\hline \multirow[t]{2}{*}{ Variable } & \multirow[t]{2}{*}{ Reference category } & \multicolumn{4}{|c|}{ SOC visits ( 4 - 12 months) } \\
\hline & & IRR (95\% CI) & $P$-value & $\operatorname{aIRR}^{\mathrm{a}}(95 \% \mathrm{Cl})$ & $P$-value \\
\hline Moderate or severe disability (3-5) & & $1.520(1.344,1.719)$ & $<0.001$ & $1.564(1.197,2.043)$ & 0.001 \\
\hline Mini-mental state examination & No cognitive impairment (24-30) & & 0.007 & & \\
\hline Mild cognitive impairment (18-23) & & $1.078(0.939,1.237)$ & & & \\
\hline Severe cognitive impairment (1-17) & & $1.266(1.092,1.466)$ & & & \\
\hline Discharge to community hospital & No & $1.475(1.307,1.665)$ & $<0.001$ & $1.362(1.015,1.826)$ & 0.039 \\
\hline $\begin{array}{l}\text { Centre for epidemiological studies } \\
\text { depression scale }\end{array}$ & & $0.996(0.985,1.007)$ & 0.445 & & \\
\hline
\end{tabular}

Abbreviations: IRR incidence rate ratio, alRR adjusted incidence rate ratio, $C l$ confidence interval, $F D W$ foreign domestic worker

${ }^{a}$ Model adjusted for age, gender, ethnicity and ward class of the patient

\section{Abbreviations}

CCl: Charlson Comorbidity Index; Cl: Confidence interval; IRR: Incidence rate ratio; MMSE: Mini-Mental State Examination; mRS: Modified Rankin Scale; NIHSS: National Institute of Health Scale; PC: Primary care; SOC: Specialist outpatient care.

\section{Supplementary Information}

The online version contains supplementary material available at https://doi. org/10.1186/s12875-021-01405-z.

\section{Additional file 1.}

\section{Acknowledgements}

We would like to thank the medical staff at the public tertiary hospitals for assisting with the recruitment of patients and their caregivers. We would also like to thank all the participants in our study for their participation and cooperation.

\section{Authors' contributions}

ST was involved in conceptualization and design of the study, analysis and interpretation of data, original draft preparation and incorporating revisions in manuscript based on critical inputs from other co-authors. GCHK was involved in conceptualization and design of the study, acquisition of data, drafting of the manuscript and providing critical inputs to revision of manuscript along with supervision of the study. NL was involved in conceptualization and design of the study, acquisition of data, drafting of the manuscript and providing critical inputs to revision of manuscript. KBT was involved in conceptualization and design of the study, acquisition of data, drafting of the manuscript and providing critical inputs to revision of manuscript. HH made substantial contributions to conception and design of the study specifically with provision of expertise in medical domain and was involved in revising the manuscript critically for intellectual content. DBM made substantial contributions to conception and design of the study specifically with provision of expertise in medical domain and was involved in revising the manuscript critically for intellectual content. JY made substantial contributions to conception and design of the study specifically with provision of expertise in financial domain and was involved in revising the manuscript critically for intellectual content. AC made substantial contributions to conception and design of the study specifically with provision of expertise in social domain and was involved in revising the manuscript critically for intellectual content. KEL was involved in acquisition of data and in revising the manuscript critically for intellectual content. NV was involved in acquisition of data and in revising the manuscript critically for intellectual content. EM was involved in acquisition of data and in revising the manuscript critically for intellectual content. KMC was involved in acquisition of data and in revising the manuscript critically for intellectual content. DADS was involved in acquisition of data and in revising the manuscript critically for intellectual content. PY was involved in acquisition of data and in revising the manuscript critically for intellectual content. BYT was involved in acquisition of data and in revising the manuscript critically for intellectual content. EC was involved in acquisition of data and in revising the manuscript critically for intellectual content. SHY was involved in acquisition of data and in revising the manuscript critically for intellectual content. YSN was involved in acquisition of data and in revising the manuscript critically for intellectual content. TMT was involved in acquisition of data and in revising the manuscript critically for intellectual content. YHA was involved in acquisition of data and in revising the manuscript critically for intellectual content. KHK was involved in acquisition of data and in revising the manuscript critically for intellectual content. RS was involved in acquisition of data and in revising the manuscript critically for intellectual content. RAM was involved in acquisition of data and in revising the manuscript critically for intellectual content. HMC was involved in acquisition of data and in revising the manuscript critically for intellectual content. TTY was involved in acquisition of data and in revising the manuscript critically for intellectual content. CN was involved in acquisition of data and in revising the manuscript critically for intellectual content. AC was involved in acquisition of data and in revising the manuscript critically for intellectual content. YLN was involved in acquisition of data and in revising the manuscript critically for intellectual content. CST was involved in conceptualization and design of the study, analysis and interpretation of data, drafting of the manuscript and providing critical inputs to revision of manuscript. All the authors have read and approved the final version of the manuscript to be published and are agreeable to take accountability of all aspects of the work involved in the manuscript.

\section{Funding}

The Singapore Stroke Study was funded by a Health Services Research Competitive Research Grant from the National Medical Research Council, Singapore. This research is supported by the Singapore Ministry of Health's National Medical Research Council under the Centre Grant Programme - Singapore Population Health Improvement Centre (NMRC/CG/C026/2017_NUHS).

\section{Availability of data and materials}

The datasets used and analysed during the current study are available from the corresponding author on reasonable request.

\section{Declarations}

Ethics approval and consent to participate

The Singapore Stroke Study was approved by the National University of Singapore Institutional Review Board, SingHealth Centralised Institutional Review Board and the National Health Group Domain Specific Review Board. Written informed consent was obtained from both the patients and the caregivers in their preferred language by trained researchers.

\section{Competing interests}

The authors declare that they have no competing interests.

\section{Author details}

${ }^{1}$ Saw Swee Hock School of Public Health, National University of Singapore, 12 Science Drive 2,\#10-01, Singapore 117549, Singapore. ${ }^{2}$ Policy Research \& Economics Office, Ministry of Health, Singapore, Singapore. ${ }^{3}$ Physical Medicine and Rehabilitation Service, Durham VA Medical Centre, Durham, NC, USA.

${ }^{4}$ Program in Health Services and Systems Research, Duke-NUS Medical School, 
Singapore, Singapore. ${ }^{5}$ Lee Kim En Neurology Pte Ltd, Singapore, Singapore. ${ }^{6}$ Raffles Neuroscience Centre, Raffles Hospital, Singapore, Singapore. ${ }^{7}$ St. Andrew's Community Hospital, Singapore, Singapore. ${ }^{8}$ Mount Alvernia Hospital, Singapore, Singapore. ${ }^{9}$ National Neuroscience Institute, Singapore General Hospital Campus, Singapore, Singapore. ${ }^{10}$ Geriatric Medicine, Khoo Teck Puat Hospital, Singapore, Singapore. ${ }^{11}$ St. Luke's Hospital, Singapore, Singapore. ${ }^{12}$ Department of Rehabilitation Medicine, National University Hospital, Singapore, Singapore. ${ }^{13}$ Department of Rehabilitation Medicine, Changi General Hospital, Singapore, Singapore. ${ }^{14}$ Department of Rehabilitation Medicine, Singapore General Hospital, Singapore, Singapore. ${ }^{15}$ Department of Neurology, National Neuroscience Institute, Neurology, Tan Tock Seng Hospital, Singapore, Singapore. ${ }^{16}$ Department of Rehabilitation Medicine, Tan Tock Seng Hospital, Singapore, Singapore. ${ }^{17}$ Department of Medicine, Yong Loo Lin School of Medicine, National University of Singapore, Singapore, Singapore. ${ }^{18}$ Department of Neurosurgery, National University Hospital, Singapore, Singapore.

Received: 24 October 2020 Accepted: 22 February 2021 Published online: 14 April 2021

\section{References}

1. Strong K, Mathers C, Bonita R. Preventing stroke: saving lives around the world. Lancet Neurol. 2007;6(2):182-7.

2. Singapore burden of disease study 2010. Ministry of Health (MOH).

3. Top ten causes of hospitalization. Ministry of Health $(\mathrm{MOH})$, Singapore.

4. Principle causes of death. Ministry of Health $(\mathrm{MOH})$, Singapore.

5. Obembe AO, Simpson LA, Sakakibara BM, Eng JJ. Healthcare utilization after stroke in Canada- a population based study. BMC Health Serv Res. 2019;19(1):192.

6. Broderick JP, Abir M. Transitions of care for stroke patients: opportunities to improve outcomes. Circ Cardiovasc Qual Outcomes 2015; 8(6_suppl_3):S190-S192.

7. Gillick MR. The critical role of caregivers in achieving patient-centered care. JAMA. 2013;310(6):575-6.

8. Pindus DM, Mullis R, Lim L, Wellwood I, Rundell AV, Aziz NAA, Mant J. Stroke survivors' and informal caregivers' experiences of primary care and community healthcare services-a systematic review and meta-ethnography. PLoS One 2018;13(2):e0192533.

9. Roth DL, Sheehan OC, Huang J, Rhodes JD, Judd SE, Kilgore M, Kissela B, Bettger JP, Haley WE. Medicare claims indicators of healthcare utilization differences after hospitalization for ischemic stroke: Race, gender, and caregiving effects. Int J Stroke. 2016;11(8):928-34.

10. Clark AN, Sander AM, Pappadis MR, Evans LG, Chiou-Tan FY. Caregiver characteristics and their relationship to health service utilization in minority patients with first episode stroke. NeuroRehabilitation. 2010;27(1):95-104.

11. Tan KB, Earn Lee C. Integration of primary care with hospital services for sustainable universal health coverage in Singapore. Health Syst Reform. 2019;5(1):18-23.

12. Khoo HS, Lim YW, Vrijhoef HJ. Primary healthcare system and practice characteristics in Singapore. Asia Pac Fam Med. 2014;13(1):8.

13. Tyagi S, Koh GC, Luo N, Tan KB, Hoenig H, Matchar DB, Yoong J, Chan A, Lee KE, Venketasubramanian N. Dyadic approach to post-stroke hospitalizations: role of caregiver and patient characteristics. BMC Neurol. 2019;19(1):267.

14. Tyagi S, Koh GC-H, Nan L, Tan KB, Hoenig H, Matchar DB, Yoong J, Finkelstein EA, Lee KE, Venketasubramanian N. Healthcare utilization and cost trajectories post-stroke: role of caregiver and stroke factors. BMC Health Serv Res. 2018;18(1):881.

15. Tyagi S, Koh GC-H, Luo N, Tan KB, Hoenig H, Matchar DB, Yoong J, Chan A, Lee KE, Venketasubramanian N. Dyadic approach to supervised community rehabilitation participation in an Asian setting post-stroke: exploring the role of caregiver and patient characteristics in a prospective cohort study. BMJ open. 2020;10(4):e036631.

16. Tyagi S, Koh GC-H, Luo N, Tan KB, Hoenig H, Matchar DB, Yoong J, Finkelstein EA, Lee KE, Venketasubramanian N. Can caregivers report their care recipients' post-stroke hospitalizations and outpatient visits accurately? Findings of an Asian prospective stroke cohort. BMC Health Serv Res. 2018;18(1):817.
17. Tan L, Yap P, Ng WY, Luo N. Exploring the use of the dementia management strategies scale in caregivers of persons with dementia in Singapore. Aging Ment Health. 2013;17(8):935-41.

18. Charlson ME, Pompei P, Ales KL, MacKenzie CR. A new method of classifying prognostic comorbidity in longitudinal studies: development and validation. J Chronic Dis. 1987:40(5):373-83.

19. Kasner SE. Clinical interpretation and use of stroke scales. Lancet Neurol. 2006;5(7):603-12.

20. Kwon S, Hartzema AG, Duncan PW, Min-Lai S. Disability measures in stroke relationship among the Barthel Index, the functional independence measure, and the Modified Rankin Scale. Stroke. 2004:35(4):918-23.

21. Ng T-P, Niti M, Chiam P-C, Kua E-H. Ethnic and educational differences in cognitive test performance on mini-mental state examination in Asians. Am J Geriatr Psychiatry. 2007;15(2):130-9.

22. Downey RG, King CV. Missing data in Likert ratings: a comparison of replacement methods. J Gen Psychol. 1998;125(2):175-91.

23. Long JS, Freese J. Regression models for categorical dependent variables using Stata. College Station: Stata Press; 2006.

24. Vuong QH. Likelihood ratio tests for model selection and non-nested hypotheses. Econometrica. 1989:57(2):307-33.

25. StataCorp. Stata statistical software: release 14. College Station: StataCorp LP; 2015.

26. Cameron Jl, Gignac MA. "Timing It Right": a conceptual framework for addressing the support needs of family caregivers to stroke survivors from the hospital to the home. Patient Educ Couns. 2008;70(3):305-14.

27. Lutz BJ, Ellen Young M, Cox KJ, Martz C, Rae Creasy K. The crisis of stroke: experiences of patients and their family caregivers. Top Stroke Rehabil. 2011;18(6):786-97.

28. Leppert MH, Sillau S, Lindrooth RC, Poisson SN, Campbell JD, Simpson JR. Relationship between early follow-up and readmission within 30 and 90 days after ischemic stroke. Neurology. 2020;94(12):e1249-58.

29. Redfern J, McKevitt C, Rudd AG, Wolfe CD. Health care follow-up after stroke: opportunities for secondary prevention. Fam Pract. 2002;19(4):378-82.

30. Wee SL, Tan CG, Ng HS, Su S, Tai VU, Flores JV, Khoo DH. Diabetes outcomes in specialist and general practitioner settings in Singapore: challenges of right-siting. Ann Acad Med Singapore. 2008;37(11):929.

31. George PP, Oh CM, Loh PT, Heng BH, Lim FS. Right-siting chronic kidney disease care-a survey of general practitioners in Singapore. Ann Acad Med Singapore. 2013;42(12):646-56.

32. Tham LM, Prabhakaran L, Lim YH, Sun B, Neo LP, Rashid SSFA. The outcome of right siting patient to primary care provider by asthma nurses. Clin Translat Allergy. 2015;5(2):1-1.

33. Bonin-Guillaume S, Durand A-C, Yahi F, Curiel-Berruyer M, Lacroix O, Cretel E, Alazia M, Sambuc R, Gentile S. Predictive factors for early unplanned rehospitalization of older adults after an ED visit: role of the caregiver burden. Aging Clin Exp Res 2015; 27(6):883-891.

34. Miller EA, Rosenheck RA, Schneider LS. Caregiver burden, health utilities, and institutional service use in Alzheimer's disease. Int J Geriatr Psychiatry. 2012;27(4):382-93.

35. Kao HFS, McHugh ML. The role of caregiver gender and caregiver burden in nursing home placements for elderly Taiwanese survivors of stroke. Res Nurs Health. 2004;27(2):121-34.

36. Thorpe JM, Sleath BL, Thorpe CT, Van Houtven CH, Blalock SJ, Landerman LR, Campbell WH, Clipp EC. Caregiver psychological distress as a barrier to influenza vaccination among community-dwelling elderly with dementia. Med Care. 2006:44(8):713-21.

37. Bradford A, Kunik ME, Schulz P, Williams SP, Singh H. Missed and delayed diagnosis of dementia in primary care: prevalence and contributing factors. Alzheimer Dis Assoc Disord. 2009;23(4):306-14.

38. Dai B, Mao Z, Mei J, Levkoff S, Wang H, Pacheco M, Wu B. Caregivers in China: knowledge of mild cognitive impairment. PLoS ONE. 2013;8(1):e53928.

39. Perry-Young L, Owen G, Kelly S, Owens C. How people come to recognise a problem and seek medical help for a person showing early signs of dementia: a systematic review and meta-ethnography. Dementia. 2018;17(1):34-60.

40. Thorpe JM, Van Houtven CH, Sleath BL. Barriers to outpatient care in community-dwelling elderly with dementia: the role of caregiver life satisfaction. J Appl Gerontol. 2009;28(4):436-60. 
41. Arbaje Al, Wolff JL, Yu Q, Powe NR, Anderson GF, Boult C. Postdischarge environmental and socioeconomic factors and the likelihood of early hospital readmission among community-dwelling medicare beneficiaries. Gerontologist. 2008;48(4):495-504.

42. Skinner KM, Tennstedt SL, Crawford SL. Do characteristics of informal caregivers affect the length of hospital stay for frail elders? J Aging Health. 1994:6(2):255-69.

43. Lewis CL, Wickstrom GC, Kolar MM, Keyserling TC, Bognar BA, Dupre CT, Hayden J. Patient preferences for care by general internists and specialists in the ambulatory setting. J Gen Intern Med. 2000;15(2):75-83.

44. Primary Care Survey 2014. In. Singapore: Ministry of Health (MOH), Singapore.

45. Dawson J, Lees JS, Chang T-P, Walters MR, Ali M, Davis SM, Diener $\mathrm{H}-\mathrm{C}$, Lees KR. Association between disability measures and healthcare costs after initial treatment for acute stroke. Stroke. 2007;38(6):1893-8.

46. Mittmann N, Seung SJ, Hill MD, Phillips SJ, Hachinski V, Coté R, Buck BH, Mackey A, Gladstone DJ, Howse DC. Impact of disability status on ischemic stroke costs in Canada in the first year. Can J Neurol Sci. 2012;39(6):793-800.

47. Matchar DB, Bilger M, Do YK, Eom K. International comparison of poststroke resource use: a longitudinal analysis in Europe. I Stroke Cerebrovasc Dis. 2015;24(10):2256-62.

48. Lutz BJ, Young ME, Creasy KR, Martz C, Eisenbrandt L, Brunny JN, Cook C. Improving stroke caregiver readiness for transition from inpatient rehabilitation to home. Gerontologist. 2016;57(5):880-9.

49. Sperber NR, Boucher NA, Delgado R, Shepherd-Banigan ME, McKenna K, Moore M, Barrett R, Kabat M, Van Houtven CH. Including family caregivers in seriously III veterans' care: a mixed-methods study. Health Affairs. 2019;38(6):957-63.

\section{Publisher's Note}

Springer Nature remains neutral with regard to jurisdictional claims in published maps and institutional affiliations.

- fast, convenient online submission

- thorough peer review by experienced researchers in your field

- rapid publication on acceptance

- support for research data, including large and complex data types

- gold Open Access which fosters wider collaboration and increased citations

- maximum visibility for your research: over $100 \mathrm{M}$ website views per year

At BMC, research is always in progress.

Learn more biomedcentral.com/submissions 